\title{
PReS-FINAL-2360: Severe disease course of pediatric-onset granulomatosis with polyangiitis as compared to adult patients: a long-term, single center, follow up study
}

\author{
G Minardo $^{1 *}$, V Carraro ${ }^{2}$, G Martini ${ }^{1}$, L Murer ${ }^{1}$, F Vittadello ${ }^{1}$, F Schiavon ${ }^{1}$, F Zulian ${ }^{1}$ \\ From 20th Pediatric Rheumatology European Society (PReS) Congress \\ Ljubljana, Slovenia. 25-29 September 2013
}

\section{Introduction}

Granulomatosis with polyangiitis (GPA) is a rare disease in childhood. Treatment strategies and clinical approach are still mostly derived from adult GPA studies.

\section{Objectives}

The present study was aimed to compare disease onset and course, therapeutic approach and clinical outcome of two cohorts of children and adults affected by GPA.

\section{Methods}

The study included children and adult patients selected on the basis of complete data set and follow up of at least one year, followed at the pediatric and adult Rheumatology Centers, University Hospital of Padua, over a period of 20 years (1993-2013). GPA was diagnosed according to the ACR and EULAR/PRES criteria. Clinical features, instrumental findings, laboratory parameters and therapeutic regimens of both cohorts were analyzed at diagnosis, six months later (T6) and at the last follow-up visit. Disease activity was assessed by the Birmingham Vasculitis Activity Score (BVAS) modified for GPA.

\section{Results}

Ten children with mean age at disease onset of 10.3 years (range 3-15) entered the study, 6/9 were female. Mean follow-up time was 8.4 years (range 2.5-18). Of the 23 adults $65.3 \%$ were female, mean age at onset 53 years (range 37-71) and mean follow-up 1.9 years (range 1-3.5). At disease onset, BVAS, clinical features and laboratory parameters of the two cohorts were not significantly different. BVAS decreased more slowly in children (p 0.002). As for internal organs involvement, renal disease was significantly higher at $\mathrm{T} 6$ and persisted over time in children ( $p$ 0.003). Similarly, pulmonary disease remained elevated at T6 while decreased over $50 \%$ in adults ( $\mathrm{p}$ 0.01). At the last $\mathrm{F} / \mathrm{U}$ visit, eye involvement was present in $44 \%$ of children while no adult showed signs of ocular disease ( $p$ 0.004). Regarding to the treatment strategies, immunosuppressive drugs were more widely used in children at diagnosis ( $p$ 0.06) and biological agents were used at an earlier disease stage than adults. Despite the longer follow up, all children were still on treatment at the last visit while $17 \%$ of adults were off therapy.

\section{Conclusion}

Adults and children with GPA had similar disease activity at onset. However, childhood GPA had a more severecourse due to persistent renal, pulmonary and eye involvement. Lower disease activity was obtained with a more aggressive treatment approach although no pediatric patients reached a treatment-free remission.

\section{Disclosure of interest}

None declared.

\section{Authors' details}

${ }^{1}$ Department of Pediatrics, University of Padua, Padua, Italy. ${ }^{2}$ Division of

Rheumatology, University of Padua, Padua, Italy. 
- Convenient online submission

- Thorough peer review

- No space constraints or color figure charges

- Immediate publication on acceptance

- Inclusion in PubMed, CAS, Scopus and Google Scholar

- Research which is freely available for redistribution 